\title{
Spatial aggregation of time variant stream water ages in urbanizing catchments
}

\begin{tabular}{|r|l|}
\hline Journal: & Hydrological Processes \\
\hline Manuscript ID: & HYP-14-0990.R1 \\
\hline Wiley - Manuscript type: & Scientific Briefing \\
\hline Date Submitted by the Author: & 21-Mar-2015 \\
\hline Keymote List of Authors: & $\begin{array}{l}\text { Soulsby, Chris; University of Aberdeen, School of Geosciences } \\
\text { Birkel, Christian; University of Costa Rica, Department of Geography } \\
\text { Geris, Josie; University of Aberdeen, School of Geosciences } \\
\text { Tetzlaff, Doerthe; University of Aberdeen, School of Geosciences }\end{array}$ \\
\hline & $\begin{array}{l}\text { isotopes, transit times, conceptual models, non-stationarity, urban } \\
\text { hydrology }\end{array}$ \\
\hline
\end{tabular}

\section{SCHOLARONE ${ }^{\text {M }}$}

Manuscripts 
$3{ }^{1}$ School of Geosciences, University of Aberdeen, Aberdeen, AB24 3UF.

$4 \quad{ }^{2}$ Department of Geography, University of Costa Rica, 2060 San José, Costa Rica. 5

6 ABSTRACT

7 We calibrated an integrated flow-tracer model to simulate spatially distributed isotope time series in 8 stream water in a $7.9 \mathrm{~km}^{2}$ catchment with an urban area of $13 \%$. The model used flux tracking to 9 estimate the time-varying age of stream water at the outlet and both urbanised $\left(1.7 \mathrm{~km}^{2}\right)$ and non10 urban $\left(4.5 \mathrm{~km}^{2}\right)$ sub-catchments over a 2.5 year period. This included extended wet and dry spells 11 where precipitation equated to $>10$ year return periods. Modelling indicated that stream water 12 draining the most urbanised tributary was youngest with a Mean Transit Time (MTT) of 171 days 13 compared with 456 days in the non-urban tributary. For the larger catchment the MTT was 280 days. 14 Here, the response of urban contributing areas dominated smaller and more moderate runoff 15 events, but rural contributions dominated during the wettest periods, giving a bimodal distribution 16 of water ages. Whilst the approach needs refining for sub-daily time steps, it provides a basis for 17 projecting the effects of urbanisation on stream water transit times and their spatial aggregation. This offers a novel approach for understanding the cumulative impacts of urbanisation on stream water quantity and quality which can contribute to more sustainable management.

Keywords: isotopes, transit times, conceptual models, non-stationarity, urban hydrology

\section{INTRODUCTION}

23 Advances in quantifying the travel times of water through catchments have shown that this depends on the interaction of flow path partitioning, the size and nature of the soil and groundwater stores 
25 and the associated mixing processes that assimilate precipitation into storage (McDonnell et al., 26 2010). An important insight has been awareness of time variant influences on transit time 27 distributions (TTDs) as highlighted by Rodhe et al. (1996). This time variance reflects the role of 28 short-term individual storm event characteristics and antecedent conditions (Birkel et al., 2012) i the 29 effects of seasonal and inter-annual climatic variability (Hrachowitz et al., 2013; Heidbuechel et al., 30 2013), the mixing assumptions for different stores (Fenicia et al., 2010; van der Velde et al., 2014)

31 and the impact of extreme events (Lyon et al., 2008). Sensitivity of catchment TTDs thus varies 32 geographically depending upon catchment characteristics and the variation in hydroclimate (Tetzlaff 33 et al., 2009). Full understanding is predicated on long-term data sets charactering climatic variability 34 (Hrachowitz et al., 2009), high resolution tracer sampling to capture short-term dynamics (Roa35 Garcia and Weiler, 2010), characterisation of older waters (Stewart et al., 2010) and identification of ecohydrologically relevant mixing of waters and solutes (Brooks et al., 2009). Only then can the response of catchments be tracked as it transits through dry periods and times of extreme wetness.

More sophisticated modelling approaches are also needed to capture time variant processes that govern the routing of water and solutes. These should ideally go beyond traditional lumped, timeinvariant convolution approaches to fitting TTDs to input-output data. Recent developments include more robust theoretical frameworks for modelling the temporal dynamics of water and solute transport (Botter et al., 2011; Duffy, 2010 Heidbuechel et al., 2012; Rinaldo et al., 2011), use of conceptual rainfall-runoff models to track tracer fluxes and water ages (Dunn et al., 2010; McGuire et al., 2007; Hrachowitz et al., 2013) and the use of particle tracking to simulate evolution of stream water transit time distributions (Davies et al., 2013). Such models should - ideally - have minimum

47 parameterisation to improve identifiability and reduce uncertainty (Beven, 2012). In this regard 48 using both flow and tracers metrics in combined objective functions allows to constrain model 49 structures, improve calibration and aid model evaluation (Birkel et al., 2014). 
51 Such coupled flow-tracer models can provide a step forward for using time variant transit time 52 analysis in applied hydrology. McDonnell and Beven (2014) identified consistent conceptualisation of 53 hydrological response celerity with pore water velocities distributions as a major research frontier in 54 hydrology. Progress is needed to produce models that can adequately characterise the hydrological 55 response dynamics, storage characteristics and mixing relationships in catchments. Only then can 56 robust projections be made about how catchments mediate impacts of land use change on stream 57 water quantity and quality in terms of routing, storage dynamics and transit times (Gall et al., 2013).

58 Monitoring effects of land use change on tracer dynamics, thus, provides an opportunity for testing 59 such integrated modelling approaches. It also provides an experimental framework for testing 60 hypotheses about how flow partitioning, storage dynamics and water transit times change. 61 Urbanisation provides rapid, direct and large-scale hydrological impacts that affect extensive parts of 62 the world (Grimm et al., 2008). This has policy relevance as more sustainable approaches to urban 63 planning seek to retain catchment storage functions by minimising the extent of impermeable 64 surfaces and creating retention wetlands to mitigate increased flood risk, reduced summer low flows 65 and deterioration of water quality (e.g. Niemczynowicz, 1999; Zipperer et al., 2000). This can be 66 assisted by understanding how the urban environment affects transit times. Here we use spatially distributed tracer data from an urbanising catchment which transitioned through some hydroclimatic extremes over a 2.5 year period. These are used together with a coupled flow-tracer model to answer the following questions: (1) What are the time-variant characteristics of the age composition of stream water draining urban and non-urban environments?

72 (2) How is the time-variance of stream water age composed in relation to the influence of different 73 land uses at larger scales? (3) Can we use such models to predict the impact of urbanisation on the 
74 stream water age? We also highlight research needs for such work to inform the development of

75 green infra-structure to facilitate more sustainable approaches to managing urban water.

\section{STUDY AREA AND DATA}

78 The study site is the Burn of Bennie, a $7.9 \mathrm{~km}^{2}$ catchment (Fig. 1 and Table 1 ) in NE Scotland. Two

79 tributaries with similar soils, geology and topography, form the headwaters; one rural in the north

80 has $\sim 1 \%$ urban influence and drains a patch work of forest, wetland and farmland. The southern

81 tributary has been subject to increased urbanisation over the past two decades (now covering $12.4 \%$

82 of its area), with the lower catchment downstream of the main tributary confluence being similarly

83 impacted (13.1\% total). Further urban expansion is planned around the southern tributary,

84 increasing the total urbanised area of the catchment to $16.3 \%$

85 (http://aberdeenshire.gov.uk/statistics/area/BanchoryProfile2013.pdf). The climate is temperate;

86 mean annual precipitation is $950 \mathrm{~mm}$ (varying between $\sim 700-1000 \mathrm{~mm}$ ), mean July and December

87 temperatures are $13^{\circ} \mathrm{C}$ and $7^{\circ} \mathrm{C}$, respectively. Potential evapotranspiration is $500 \mathrm{~mm}$ and fairly

88 constant. The catchment is underlain by a uniform, low permeability bedrock covered by deep (10-

$8920 \mathrm{~m}$ ) layers of glacial drift, with alluvium in the river valleys. The drifts are coarse textured and

90 podzolic soils, which are mainly freely-draining, dominate.

92 Five sites were sampled from October 2011 at approximately weekly intervals (Fig. 1 and Table 1).

93 These include the main catchment outfall (ID=outlet), and the lowest points on the rural (ID=rural)

94 and urban tributaries (ID=urban). Also, a site on the upper urban tributary was sampled (ID=urban a)

95 as was the outflow from a retention pond draining a recently urbanised area (ID=urban b). Sampling

96 targeted hydrological events; most significant events were sampled and larger events were sampled

97 daily over the hydrograph. Daily precipitation samples were collected from a small weather station 
98 (Fig. 1). Samples were analysed at the University of Aberdeen for ${ }^{18} \mathrm{O}$ and ${ }^{2} \mathrm{H}$ using a Los Gatos DLT-

99100 (2nd generation) laser spectrometer and are reported in $\delta$ units (\%o) relative to Vienna Standard 100 Mean Ocean Water (V-SMOW). Analytical precision was $0.2 \%$ for $\delta^{18} \mathrm{O}$ and $0.4 \%$ for $\delta^{2} \mathrm{H}$. Given the greater relative precision we use $\delta^{2} \mathrm{H}$ in the modelling that follows.

Precipitation data from 14 surrounding daily gauges were used from the MIDAS data sets at the

British Atmospheric Data Centre to derive daily areal totals via spatial interpolation with the gradient

inverse distance method (Stahl et al., 2006) on a $100 \mathrm{~m}$ grid. An Automatic Weather Station $10 \mathrm{~km}$

south of the site was used to derive ET estimates for the catchment using Penman-Monteith. Due to

vandalism problems, continuous flow gauging in the urban catchment was precluded. Thus, we used

the method of Seibert and Beven (2009) to manually gauge flows (10 gaugings in total) across the

flow spectrum as calibration targets for a runoff model to produce flow time series. This was found

to give acceptable estimates of daily flows at the rural, urban and outlet sites (see Soulsby et al.,

111 2014).

112

\section{INTEGRATED FLOW-TRACER MODEL}

\section{$114 \quad 3.1$ Model structure}

115 We used the data to develop a simple conceptual, tracer-aided rainfall-runoff model representing

116 the two main landscape units (urban and rural) combined in three sub-catchments represented by

117 the rural, urban and outlet sites (Figure 2). After testing different arrangements of the stores in the

118 model we settled on the most parsimonious semi-distributed structure. This consisted of a single

119 linear reservoir draining urban areas (storage component $S_{\text {urban }}$ drained by the rate parameter $u$ ) and

120 a two-reservoir model for rural areas. The upper reservoir $S_{u p}$ was parameterised (rate parameters $k$ 
122 flow components. The lower reservoir $S_{\text {low }}$ is filled by a linear recharge flux (parameter $r$ ) and linearly

123 contributes to streamflow via the rate parameter $b$. Both components add up to total stream flow.

124 For mixed landscape sub-catchments, the rural and urban model units were combined, with the 125 areal fraction of their flow-tracer contribution to the catchment outlet summing to one.

126

127 Tracer transport and mixing was directly linked to the hydrological reservoirs using a mixing cell 128 approach similar to Hrachowitz et al. (2013):

$129 \frac{d(c S)}{d t}=\sum_{j} c_{I, j} I_{j}-\sum_{k} c_{O, k} O_{k}$

Eq. 1

130 With $c$ being the isotope signature of storage components (\%o) in $j$ storage inflows $l_{j}$ (precipitation

131 and recharge) and $k$ outflow $O_{k}$ components (actual evapotranspiration $E T_{\text {act }}$ and upper reservoir 132 outflow $Q_{u p}$ ), which characterizes the catchment storage $S$ dynamics (sum of dynamic and additional 133 storage components available for mixing that do not affect the water fluxes) and associated isotope 134 signature $c$. Additional mixing stores were calibration parameters in the form of fixed mixing 135 volumes $\left(M V_{\text {up }}\right.$ in $S_{\text {up }}$ and $M V_{\text {low }}$ in $\left.S_{\text {low }}\right)$. These facilitate reproduction of observed tracer attenuation 136 in streams. As urban reservoirs are assumed to directly contribute tracers to the stream no mixing 137 parameters were used. We did not incorporate isotopic fractionation as tests did not show an 138 improvement to simulations. For the different subcatchments, the same parameters were applied to 139 represent the same landscape units and keep the model as parsimonious as possible (7 parameters 140 in total; 5 rainfall-runoff and 2 tracer parameters as indicated in Fig. 2).

\section{$141 \quad 3.2$ Water age estimates}

142 We used a flux tracking approach (Hrachowitz et al., 2013) to estimate water age. As each new daily 143 input flux can be labelled, the evolving age of water in different stores can be tracked to give a final 144 age label upon discharge to the stream. The stream water age is then calculated as a flux-weighted 
145 age from the contributions of the urban and upper and lower reservoirs. Time variant water age 146 distributions for flow generated from the different units and sub-catchments was then calculated:

$147 \quad p_{F, Q}\left(t_{j}-t_{i}, t_{j}\right)=\sum_{n=1}^{N} p_{F, Q_{n}}\left(t_{j}-t_{i}, t_{j}\right) \frac{Q_{n}\left(t_{j}\right)}{Q\left(t_{j}\right)}$

148 Where $p_{F, Q}$ is the distribution of water age of contributing fluxes $Q_{n}$ to total discharge $Q$ with $t_{j}$ being 149 the time of exit at the catchment outlet and $t_{i}$ the time of entry with precipitation. Simulations used 150 a 5 year warm-up period to initialise storage filling, signatures and water ages (starting at 1 with the 151 first day of simulations). Isotope storage values were initially set to observed mean discharge 152 signatures for each site. Actual planning proposals for new urban areas (Fig. 1) were used to predict 153 impacts on water age distributions using the calibrated model, assuming a stationary climate.

\subsection{Model calibration}

We integrated calibration objectives using the manual point gaugings for the streamflow targets and isotope time series measured at the urban, rural, and outlet sub-catchments as the tracer targets. We also used the ratio of measured flows of the rural and urban sub-catchments as an additional 159 stream flow target. Calibration used the modified Kling-Gupta efficiency (KGE) for the two separate 160 (streamflow KGE_Q and tracer KGE_D) objectives (Kling et al., 2012):

$$
K G E=1-\sqrt{(1-r)^{2}+(1-\gamma)^{2}+(1-\beta)^{2}}
$$

Eq. 3

The KGE is a three-dimensional representation (Euclidean distance) of the widely-used NashSutcliffe criterion balancing dynamics (correlation coefficient $r$ ), bias (bias ratio $\beta$ ) and variability 164 (variability ratio $y$ ) with a perfect fit of 1 . The combined streamflow and tracer targets were equally 165 weighted and minimized as the unknown Euclidean distance from the optimal model using a multiobjective Non-dominated Sorting Genetic evolution Algorithm (NSGA) (Deb et al., 2002). This 
167 searches a relatively wide initial parameter space and sequentially combines and updates 500 168 parameter sets over 1000000 iterations until no further improvement can be established. The best 169500 parameter sets were used for subsequent analysis.

\subsection{Parameter identifiability}

172 We used a regional sensitivity analysis (RSA) (Hornberger and Spear, 1981) to assess identifiability of 173 the best 500 parameter sets. The resulting curves or constrained parameter spaces indicate 174 identifiability, while a straight line over the initial parameter space shows non-identifiability.

\subsection{Lumped convolution integral model}

177 Transit times from the flow-tracer model were compared to a time invariant convolution integral 178 model (see Hrachowitz et al., 2009) using the two-parameter (shape parameter $\alpha$ and scale 179 parameter $\beta$ ) gamma distribution as a transfer function (Kirchner et al., 2001). The KGE criterion was 180 used to calibrate the gamma model (GM) with a single target (isotope time series measured for each 181 sub-catchment) using a simple Differential Evolution (DE) algorithm for optimization (Mullen et al., 182 2010). The 2.5 yr record was used for calibration with a warm-up of 5 years. Due to the insensitivity 183 of stable isotopes in detecting older water, the 6 parameter was set to the upper limit of 5 years.

185 4. RESULTS

\section{$186 \quad 4.1$ Hydroclimatic and isotopic variability}

187 During the study the site experienced a range of unusual and contrasting hydroclimatic extremes 188 (Fig. 3). The first year had a dry winter, but the summer of 2012 was the wettest for 20 years in NE 
189 Scotland In the second year, the autumn was wet and in Dec. 2012 the highest daily precipitation

190 totals and flows were recorded. This was followed by a warm dry summer in 2013 corresponding to

191 a 10 year return period drought which persisted through autumn but was followed by high 192 precipitation in both Jan. and Feb. 2014 (see UK Hydrological Summaries for individual months at 193 http://www.ceh.ac.uk/data/nrfa).

194

Isotopes in precipitation exhibited general seasonal differences between winter depletion and summer enrichment, but day-to-day variability within season was marked (Fig. 3). Isotope variability in stream flow was most pronounced in the most urbanised sites (Table 2), with urban impacts evident in rapid, direct routing of tracer signals in precipitation both in small and large events. Variations were attenuated in the rural tributary where dynamics in stream water isotope signals were exhibited more gradual changes in the wetter periods in June and Dec. 2012 and Jan/Feb 2013. At sites with both rural and urban influence, the tracer variations reflect both the urban influence of marked isotopic variability in smaller events but a general damping in large events and baseflows.

\subsection{Flow-tracer model simulation results}

The integrated flow-tracer model captured the measured peak discharge and following recession period in Dec. 2012 (Figure 4a). Additionally, the model was able to match the observed lower flows, despite failing to reproduce the higher observed flows in June 2012. However, the model did capture small and moderate events with dry antecedent conditions where the lower catchment response is dominated by the urban response. The model calibrated to the common flow target performed reasonably well with a best-fit $K G E=0.66\left(R^{2}=0.72\right)$. Also, most rainfall-runoff model parameters nonlinearity parameter $\alpha$ and the recharge rate parameter $r$. 
214 Stream isotope variations were captured quite well and the posterior variability of the best 500 215 parameter sets bracket most of the observations (Fig. 4b-d). Additional mixing volumes were 216 identifiable with a constrained upper volume $M V_{u p}$ (150 to $280 \mathrm{~mm}$ ) and an identifiable parameter 217 region of $M V_{\text {low }}$ at $>800 \mathrm{~mm}$ (Fig. 5e and f). The best isotope simulations were for the most 218 urbanised catchment; best-fit KGE of 0.86 and $R^{2}$ of 0.89 (Fig. $4 \mathrm{~d}$ ). In the rural tributary the challenge 219 of the damping was exacerbated by the effects of evaporative fractionation in the summer of 2014 220 (Fig. 4c). Thus, invariant isotope values were simulated in outflows from the lower groundwater box 221 which also failed to capture short-term effects of summer events or fractionation. This also 222 explained why isotopic fractionation tests showed little model improvement. Nevertheless, overall 223 simulations were reasonable (best-fit $K G E=0.78$ and $R^{2}=0.8$ ). The summer problems were also 224 evident to a lesser extent in the simulations for the integrated lower catchment, where the lowest 225 flows are generally dominated volumetrically by the rural catchment (Fig. 4d and Table 3). However, 226 again, overall the model performed well over the whole period (best-fit $K G E=0.83$ and $R^{2}=0.85$ ).

$228 \quad 4.3$ Spatial aggregation on stream water age estimates

229 Stream water ages were estimated by aggregating the age of water derived from flux tracking in the 230 different model landscape units, revealing marked differences for the 3 sites (Fig. 6). In the rural 231 tributary ages show a bimodal distribution (Fig. 6c and c1); with a 50-100 day peak for larger events, 232 and a secondary peak of 350-400 days reflecting the heavy tailing of old water contributions at base 233 flow. The influence of such slower, deeper flow paths is emphasised by $<50 \%$ of tracer recovery 234 being modelled at the end of a year. In contrast, the outflow of the modelled urban response unit 235 indicated the very short residence times; here, most stream water is a few days old, and about $70 \%$ 236 of the flux occurred in $<50$ days, with $>95 \%$ tracer recovery within 400 days (Fig. $6 a$ and a1). In mixed 
237 land use catchments (urban and outlet), the integration of both sources are evident (Fig. $6 \mathrm{~b}$ and c).

238 In the urban tributary, the distribution is modal in the 50-100 day age class, with limited tailing (Fig.

$2396 \mathrm{~b}$ and b1). However, at the lower site (outlet) the distribution is bi-modal with the urban area giving

240 50-100 day modal class, and rural inputs causing a secondary peak at 300-400 days (Fig. 6d and d).

The Transit Time Distribution derived using the time invariant Gamma Model fitted to the inputoutput data had lower performance statistics than the flow-tracer model though still reasonable fits

244 (Table 4). The $\alpha$ parameter in the GM was 0.63 for the rural site, but reduced to 0.2 as the percentage urban area increased. Such a decrease with increasing urban cover was also observed for the MTT. The beta parameter was not identifiable and remained close to the upper boundary of 5 years. The derived best-fit MTTs for the urban, rural and outlet sites from the GM at 366, to 1050 to 456 days respectively, were shorter than for the flux tracking. However, the posterior variability (indicated by the best 500 parameter sets) of the flow-tracer model indicates significant uncertainty 250 (Table 4) which generally brackets the GM estimates.

\subsection{Future urban development}

The model was also used for projecting future change by increasing the urban area based on actual planning proposals (Fig. 1). Resulting changes to the cumulative frequency distributions of median water ages shows accelerated routing of water and reduced storage at both the urban and outlet sites, with consequent reduced water ages (Fig. 7). The rural tributary remains unchanged. The uncertainties of the projections are large and overlap as indicated in Table 4, but the direction of change is evident in the median age distributions and consistent with impacts so far. Thus, even if relatively small parts of a catchment are affected by urbanization, this is still sufficient for a dramatic 
261 remained unchanged, just a 3\% increase in urban area showed a clear impact with the future outlet

262 median age CDF approximating the current urban site.

263

264 5. DISCUSSION

\section{What are the time-variant characteristics of stream water age of urban and non-urban streams?}

266 The integrated flow-tracer model gave an estimate of the age distribution of streams draining

267 catchments with differential levels of urbanisation. Unsurprisingly, this infers a much higher

268 proportion of newer water, and less tailing of older water, than shown in time-invariant TTD analysis

269 (see Table 4 and Soulsby et al., 2014). It is striking just how much of the precipitation in urban-

270 impacted areas appears to reach the stream within a few days, given the implications for storage

271 and low flows. However, this also reflects the model structure that simply assumed rapid runoff

272 from the urban areas, rather than for example, deeper infiltration in gardens, etc, in order to

273 maintain minimal parameterisation (Kirchner, 2006). It is clear that our model does not attempt to

274 accommodate the hydraulic infrastructure of the complex reality in urban systems. However, in the

275 absence of more spatially distributed and higher temporal resolution (sub-daily) flow and tracer data

276 to conceptualize and evaluate a more complex model, such efforts would likely result in increased

277 uncertainty (Beven, 2012). Although we did not present formal uncertainty analysis, the posterior

278 variability of the best 500 parameter sets retained after multi-objective optimization provides an

279 uncertainty proxy; Andrews et al. (2011) showed that the best parameter sets using such

280 optimization methods falls into the range of behavioural parameter sets defined using more formal

281 uncertainty analysis. Also, the model was internally constrained using isotope time series from three

282 sub-catchments resulting in generally good tracer simulations over 2.5 years of marked

283 hydroclimatic variability (Fig. 4) with mostly identifiable parameters (Fig. 5) (Birkel et al., 2014). As a

284 result the isotope simulations for the three sub-catchment time series outperformed flow 285 simulations (Table 3). 
287 Damped tracer signals increase uncertainty of simulations in the rural catchment (MTT $=473$ days with a $95^{\text {th }}$ percentile range of $326-864$ days; Table 4). A bimodal distribution was simulated with relatively young waters being derived from the upper soil reservoir in wet periods, consistent with agricultural drainage effects in the low-lying areas. However, a greater proportion of older water draining by slower flow paths gives bimodality in age distributions at about 1 year and heavier tailing beyond this. Such complex age distributions derived from conceptual models using flux tracking have also been reported by Dunn et al. (2010) and Hrachowitz et al. (2013). Notwithstanding the influence of hydroclimatic variability on stream water age, the bi-modal distributions are more consistent with differences in land use and the resulting variability in flow pathways. Such effects of variable flow pathways on TTDs was also shown by Heidbuechel et al. (2013) albeit in a more markedly seasonal semi-arid catchment in Arizona, USA. Mixing assumptions also influences timevariable TTDs (van der Velde et al., 2014) and the complete mixing used here is overly simplistic. However, the combination of three parallel reservoirs with one nonlinear parameterization creates a more dynamic catchment scale conceptualisation for assessing the time-variant TTDs.

The characterisation of TTDs achieved with the integrated flow-tracer modelling approach is an improvement on using an invariant convolution integral model (Table 4). Although these showed the same ranking of MTTs (e.g. urban site < outlet site < rural site), the resulting MTTs are longer than those produced by the time-variant modelling by a factor of 2.1 for urban, 2.4 for rural and 1.62 for the outlet showing the instability of the time invariant GM for short $(<5$ year) data time series 307 (Hrachowitz et al., 2009). Nevertheless, for both the urban and outlet sites, GM estimates fall within 308 the 95\%ile error bands of the flow-tracer model. 
310 How is time variant streamwater age affected by integration of different land use at larger scales?

311 Time variant flow-tracer modelling allowed us to develop a hypothesis of catchment function which 312 integrates the urban impact on stream water ages at different scales. This is based on the 313 integration of sub-catchments and their dominant processes in relation to land use, which can be seen as upscaling runoff generation and solute transport processes from the hillslope (e.g. Tetzlaff et al., 2014) to catchment scale. Use of multi-objective calibration targets produced a reasonable representation of the runoff and isotope response in the two main sub-catchments and at the catchment outlet (Fig. 4). The isotope damping at the rural site leads to larger uncertainties, in the summer tracer simulations, and this propagates to the outlet site. Despite this, for most of the study contributions of older water from the rural catchment in the secondary peak at 300 days (Fig. 6d). It is also notable that despite the similar percentage urban cover at the urban and outlet sites, the effect is much greater at the former, though the urban impact remains cumulative at the outlet.

Although these contrasts mainly reflect the moderating effect of the rural catchment at higher flows, they may also reflect differences in the catchment land use and the nature of the urban developments. The non-urban areas in the sub-catchment of the urban site are predominantly (59\%) rough grazing, whilst in the sub-catchment of the rural site it is mainly (64\%) forest. This is likely to result in longer residence times in the forested areas due to lower artificial drainage and greater infiltration to depth (e.g. Geris et al., 2014). In addition, urban areas in the upper catchment above the urban site are mainly housing up to 15 years old, which has a higher density of impermeable surfaces and limited sustainable urban drainage systems (soakaways, retention wetlands, etc). In 
comprises an industrial estate and retail outlets, with less dense coverage of impermeable surfaces, more green space, permeable parking areas and some retention ponds (cf. O'Driscoll et al., 2010).

Lower density urban development is likely to increase water age due to greater sub-surface storage and mixing (and therefore decrease impacts), but modelling this would require explicit integration of more detailed land use classes accompanied by corresponding data for parameterization. Such improvements to the current model are under way and future work will be directed at detailed

\section{Can we project the impact of increased urbanisation on the composition of stream water age?}

345 The flow-tracer modelling approach already shows promise as a tool for predicting change in TTDs

346 resulting from further urbanisation, with the increasing dominance of younger waters at both the 347 urban and outlet sites likely to result from the urban growth already planned in the catchment (Fig. 348 7). However, as noted, the approach is simplistic and work is needed to reduce the inherent 349 uncertainties and provide knowledge transfer for urban design. A key need is higher resolution data 350 (Kirchner et al., 2004); modelling at a daily time step is only a first approximation in assessing urban 351 effects on TTDs. Although sampling targeted high flow events, in reality, the response time of 352 impermeable urban surfaces is much less than this and will influence stream flows on a sub-hourly 353 basis during more intense precipitation (O'Driscoll et al., 2010). Thus, collecting high resolution data 354 to refine the model for sub-daily scales is needed to characterise the faster tail of the TTD and its 355 overall influence more realistically (Birkel et al., 2012). The current uncertainties are reflected in the $35695^{\text {th }}$ percentiles around the MTTs calculated from the best 500 parameter sets (Table 3 ). At the 357 outlet this results in a MTT of 280 days with $95^{\text {th }}$ percentiles of 208 to 520 days. Although these 358 ranges imply some overlap in the CDFs, the general features such as the observed bi-modality and 359 the direction of projections from rural to more urban remain unaffected. 
361 In addition, dynamics of the longer residence time waters need to be constrained by (a) using tracers 362 that can quantify ages beyond the 5 year limit of stable isotopes (Stewart et al., 2010) and (b) 363 tracking the catchment response over longer periods (Hrachowitz et al., 2009). Despite constraining 364 the older waters in the flux tracking approach by looping the observed time series, it is unlikely that 365 all potential climatic variability is captured over relatively short monitoring periods, though the 2.5 366 years used here were remarkably variable. This is illustrated by previous analysis of the data from 367 the study site in the first year which covered a relatively dry period: the characterisation of TTDs for 368 the urban and outlet sites in this case showed they were relatively similar (see Soulsby et al., 2014). 369 The new analysis presented here using the 2.5 year data set, including two wetter periods and a 370 more pronounced summer dry period (Figure 2) than were observed in the first year, showed much 371 larger water age differences than previously reported.

Finally, the model calibration resulted in substantial uncertainties stemming from the lack of 374 distributed continuous flow data, particularly from the rural tributaries and the integration of 375 temporally different flow contributions from tributaries to the catchment outlet. Whilst this does 376 not affect the general conclusions derived from daily time steps, it would be inadequate for 377 assessing the sub-daily variations described above. Future work will focus on improving monitoring 378 which in turn can be used to develop a more complex and spatially explicit model. We therefore 379 envision incorporating wetlands and soakaway systems as temporary stores, and a lower reservoir in 380 the urban store that allows infiltration to deeper flow paths, sewer overflow and drainage exports.

The model's capability in integrating intra-catchment differences in daily flow and isotope responses 
distributions is encouraging. There is clear potential use of such insights in urban planning for a sustainable water environment. If the data limitations outlined above can be overcome, an evidence base would emerge that potentially could provide specific guidance on the timescale of water fluxes that could be targets for water retention in new urban developments. This could include, for example, guidance on the design of green infrastructure such as wetlands and detention ponds or permeable surfaces to maintain storage to mitigate flood risk, sustain low flows and improve highly relevant water quality. Currently, such infrastructure is developed from guidelines that often have little specific context for the hydrology and landscape for where the development is occurring. Similarly, as urban development often occurs in a piecemeal ad hoc way, the scaling of impacts and their cumulative effects are often ignored. Whilst such issues remain substantial challenges, we present a first step to better understand the cumulative impact of urbanisation on transit times that could be used in future to create more sustainable approaches to urban water management.

\section{Conclusion}

Flux tracking is a useful tool for characterising complex time-variant water age distributions and their spatial aggregation in catchments impacted by urbanisation. Whereas previous studies have usually looked at input-output relationships for individual catchments (Hrachowitz et al., 2013) or different hydrological response units within a catchment (Birkel et al., 2014), here we have shown its utility in integrating responses from contrasting units in a mixed land cover catchment. The dramatic impact on urbanisation on the quick responding part of the TTD is captured both at the local and larger catchment scale. The flow-tracer model captured bi-modal TTDs with a higher proportion of young water and less tailing of older water than using time-invariant models. Though challenges remain, the approach provides a step towards a framework that could be used in urban design that seeks to restrict the rapid water fluxes traditionally associated with urbanisation and maintain catchment storage to sustain low flows, mitigate flood risk and ameliorate water quality impacts. 
409

410 Acknowledgements

411 The help of Clara F. Soulsby with the sampling is gratefully acknowledged.

412 
$\underline{\text { http://aberdeenshire.gov.uk/statistics/area/BanchoryProfile2013.pdf }}$

415

Andrews F, Croke B, Jakeman A. 2011. An open software environment for hydrological model assessment and development. Environmental Modelling \& Software 26: 1171-1185, doi:10.1016/j.envsoft.2011.04.006.

421

Beven K. 2012. Rainfall-runoff modelling: The Primer. Second edition. Wiley-Blackwell.

Birkel C, Soulsby C, Tetzlaff T, Dunn S, Spezia L. 2012. High frequency storm event isotope sampling reveals time-variant transit time distributions and influence of diurnal cycles. Hydrol. Processes 26(2): 308-316, doi:10.1002/hyp.8210.

Birkel C, Soulsby C, Tetzlaff D. 2014. Developing a consistent process-based conceptualization of catchment functioning using measurements of internal state variables. Water Resources Research. Doi: 10.1002/2013WR014925.

Botter G, Bertuzzo E, Rinaldo A. 2011. Catchment residence and travel time distributions: The master equation. Geophys. Res. Lett. 38: L11403, doi:10.1029/2011GL047666.

Brooks JR, Barnard HR, Coulombe R, McDonnel JJ. 2010. Ecohydrologic separation of water between trees and streams in a Mediterranean climate. Nature Geoscience 3: 100-104.

http://www.nature.com/ngeo/journal/v3/n2/full/ngeo722.html

Deb K, Pratap A, Agarwal S, Meyarivan T. 2002. A fast and elitist multi-objective genetic algorithm: NSGA-II. IEEE Transaction on Evolutionary Computation 6(2): 181-197.

Davies J, Beven K, Rodhe A, Nyberg L, Bishop K. 2013. Integrated modelling of flow and residence times at the catchment scale with multiple interacting pathways. Water Resour. Res. 49: 4738-4750, doi:10.1002/wrcr.20377.

Duffy CJ. 2010. Dynamical modeling of concentration-age-discharge in watersheds. Hydrol. Processes 24: 1711-1718, doi:10.1002/hyp.7691.

Fenicia F, Wrede S, Kavetski D, Pfister L, Hoffmann L, Savenije HHG, McDonnell JJ. Assessing the impact of mixing assumptions on the estimation of streamwater mean residence time. Hydrological Processes 24: 1730-1741, 2010.

Gall HE, Park J, Harman CJ, Rao PSC, Jawitz J. 2013. Landscape filtering of hydrologic and biogeochemical responses in managed landscapes. Journal of Landscape Ecology 28: 651-664.

Geris J, Tetzlaff D, McDonnell J, Soulsby C. 2014. The relative role of soil type and tree cover on water storage and transmission in northern headwater catchments. Hydrol. Process., doi: 10.1002/hyp.10289

Grimm NB, Faeth SH, Golubiewski NE, Redman CL, Wu J, Bai X, Briggs JM. 2008. Global change and the ecology of cities. Science 319: 756-760. 
Heidbüchel I, Troch PA, Lyon SW, Weiler M. 2012. The master transit time distribution of variable flow systems. Water Resources Research 48: 6, doi:10.1029/2011WR011293.

Heidbuechel I, Troch PA, Lyon SW. 2013. Separating physical and meteorological controls of variable transit times in zero-order catchments. Water Resour. Res. 49: doi:10.1002/2012WR013149.

Hornberger G, Spear R. 1981. An approach to the preliminary analysis of environmental systems. J. Environ. Manage. 12: 7-18.

Hrachowitz M, Soulsby C, Tetzlaff D, Dawson JJC, Dunn SM, Malcolm IA. 2009. Using long-term data sets to understand transit times in contrasting headwater catchments. J. Hydrol. 367: 237- 248.

Hrachowitz M, Soulsby C, Tetzlaff D, Malcolm IA, Schoups G. 2010. Gamma distribution models for transit time estimation in catchments: Physical interpretation of parameters and implications for time-variant transit time assessment. Water Resour. Res. 46: W10536, doi:10.1029/2010WR009148.

Hrachowitz M, Savenije H, Bogaard TA, Tetzlaff D, Soulsby C. 2013. What can flux tracking teach us about water age distribution patterns and their temporal dynamics?, Hydrology and Earth System Sciences 17: 533-564. DOI:10.5194/hess-17-533-2013.

Kirchner JW, Feng X, Neal C. 2001. Catchment-scale advection and dispersion as a mechanism for fractal scaling in stream tracer concentrations. J. Hydrol. 254: 82-101, doi:10.1016/S00221694(01)00487-5.

Kirchner JW, Feng X, Neal C, Robson AJ. 2004. The fine structure of water-quality dynamics: the (high-frequency) wave of the future. Hydrol. Process. 18: 1353-1359. doi: 10.1002/hyp.5537

Kirchner JW. 2006. Getting the right answers for the right reasons: Linking measurements, analyses, and models to advance the science of hydrology. Water Resour. Res. 42: W03S04, doi:10.1029/2005WR004362.

Kling H, Fuchs M, Paulin M. 2012. Runoff conditions in the upper Danube basin under an ensemble of climate change scenarios. J. Hydrol. 424-425: 264-277. doi:10.1016/j.jhydrol.2012.01.001.

Lyon SW, Desilets SLE, Troch PA. 2008. Characterizing the response of a catchment to an extreme rainfall event using hydrometric and isotopic data. Water Resour. Res. 44: W06413, doi:10.1029/2007 WR006259.

McDonnell JJ., et al. 2010. How old is streamwater? Open questions in catchment transit time conceptualization, modeling and analysis. Hydrol. Processes 24: 1745-1754, doi:10.1002/hyp.7796.

McDonnell JJ, Beven K. 2014. Debates - The future of hydrological sciences: A (common) path forward? A call to action aimed at understanding velocities, celerities, and residence time distributions of the headwater hydrograph. Water Resources Research 50: 5342-5350. DOI: 10.1002/2013WR015141. 
503 McGuire KJ, Weiler M, McDonnell JJ. 2007. Integrating tracer experiments with modeling to assess 504 runoff processes and water transit times. Adv. Water Resour. 30: 824-837,

505 doi:10.1016/j.advwatres.2006. 07.004.

506

Mullen K, Ardia D, Gil D, Windover D, Cline J. 2011. DEoptim: An R Package for Global Optimization 508 by Differential Evolution. Journal of Statistical Software 40(6): 1(26).

509 Niemczynowicz J. 1999. Urban hydrology and water management-present and future challenges.

510

511

512

513

514

515

516

517

518

519

520

521

522

523

524

525

Urban Water 1: 1-14.

O'Driscoll M, Clinton S, Jefferson A, Manda A, McMillan S. 2010. Urbanization Effects on Watershed Hydrology and In-Stream Processes in the Southern United States. Water, 2 (3): 605-648. doi:10.3390/w2030605.

Rinaldo A, Beven KJ, E. Bertuzzo E, Nicotina L, Davies J, Fiori A, Russo D, Botter G. 2011. Catchment travel time distributions and water flow in soils. Water Resour. Res. 47: W07537, doi:10.1029/2011WR010478.

Roa-Garcia MC, Weiler W. 2010. Integrated response and transit time distributions of watersheds by combining hydrograph separation and long-term transit time modelling. Hydrol. Earth Syst. Sci. 14(8): 1537-1549, doi:10.5194/hess-14-1537-2010.

Rodhe A, Nyberg L, Bishop K. 1996. Transit times for water in a small till catchment from a step shift in oxygen-18 content of the water input. Water Resources Research 32: 3497-3511.

Seibert J, Beven KJ. 2009. Gauging the ungauged basin: how many discharge measurements are needed? Hydrology and Earth System Sciences 13: 883-892. DOI:10.5194/hess-13-883-2009.

Soulsby C, Birkel C, Tetzlaff D. 2014. Assessing urbanization impacts on catchment transit times. Geophysical Research Letters 41: 442-448. DOI:10.1002/2013GL058716.

Stahl K, Moore RD, Floyer JA, Asplin MG, McKendry IG. 2006. Comparison of approaches for spatial interpolation of daily air temperature in a large region with complex topography and highly variable station density. Agricultural and Forest Meteorology 139: 224-236. DOI: 10.1016/j.agrformet.2006.07.004

Stewart MK, Morgenstern U, McDonnell JJ. 2010. Truncation of stream residence time: How the use of stable isotopes has skewed our concept of streamwater age and origin. Hydrological Processes 24: 1646-1659.

537 Tetzlaff D, Seibert J, McGuire KJ, Laudon H, Burns DA, Dunn SM, Soulsby C. 2009. How does 538 landscape structure influence catchment transit time across different geomorphic provinces? Hydrol. 539 Processes 23: 945-953, doi:10.1002/hyp.7240.

Tetzlaff D, Birkel C, Dick J, Geris J, Soulsby C. 2014. Storage dynamics in hydropedological units control hillslope connectivity, runoff generation, and the evolution of catchment transit time distributions. Water Resour. Res. 50: 969-985, doi: 10.1002/2013WR014147.

Thompson SE, Sivapalan M, Harman CJ, Srinivasan V, Hipsey MR, Reed P, Montanari A, Blöschl G. 2013. Developing predictive insight into changing water systems: use-inspired hydrologic science for 
547 the Anthropocene. Hydrology and Earth System Sciences 17: 5013-5039. DOI: 10.5194/hess-17-

548 5013-2013.

549

550 van der Velde Y, Heidbüchel I, Lyon SW, Nyberg L, Rodhe A, Bishop K, Troch PA. 2014. Consequences

551 of mixing assumptions for time-variable travel time distributions. Hydrological Processes DOI:

$552 \quad 10.1002 /$ hyp.10372.

553

554 Zipperer WC, Wu J, Pouyat RV, Pickett STA. 2000. The application of ecological principles to urban

555 and urbanizing land use. Ecol. Appns 10: $685-688$.

556

557 
TABLES

2 Table 1: Physical characteristics of the Burn of Bennie catchment (outlet) and the urban and rural 3 sub-catchments.

\begin{tabular}{l|c|c|c|c|c|c|c}
\hline \multicolumn{1}{c|}{ ID } & & \multicolumn{3}{c|}{ Topography } & \multicolumn{3}{c}{ Land use } \\
\hline & $\begin{array}{c}\text { Area } \\
\left(\mathrm{km}^{2}\right)\end{array}$ & $\begin{array}{c}\text { Elevation } \\
\text { range } \\
(\mathrm{m})\end{array}$ & $\begin{array}{c}\text { Mean } \\
\text { Elevation } \\
(\mathrm{m})\end{array}$ & $\begin{array}{c}\text { Mean } \\
\text { Slope } \\
\left({ }^{\circ}\right)\end{array}$ & $\begin{array}{c}\text { Urban } \\
(\%)\end{array}$ & $\begin{array}{c}\text { Forest } \\
(\%)\end{array}$ & $\begin{array}{c}\text { Agri- } \\
\text { culture } \\
(\%)\end{array}$ \\
Urban a) & 0.34 & 36 & 90 & 2.51 & 63.3 & 36.7 & 0 \\
Urban & 1.68 & 55 & 83 & 2.26 & 12.4 & 28.6 & 597 \\
Urban b) & 0.027 & 4 & 64.4 & 1.08 & 100 & 0 & 0 \\
Rural & 4.5 & 104 & 90 & 2.83 & 1.0 & 63.8 & $24.7^{*} 8$ \\
Outlet & 7.9 & 117 & 86 & 2.65 & 13.1 & 68.5 & 31.5 \\
\hline
\end{tabular}

*: $10.5 \%$ catchment area corresponds to wetland area and landfill site. 
29 Table 2: Isotope summary statistics for the 2.5 years study period (October 2011 - April 2014).

\begin{tabular}{l|l|l|r|r|r|r}
\hline ID & & $\mathrm{n}$ & \multicolumn{1}{l|}{ Mean } & \multicolumn{1}{l|}{ Min } & \multicolumn{1}{l|}{ Max } & \multicolumn{1}{l}{ SD } \\
\hline Precipitation & Un-weighted & 544 & -54.8 & -147.3 & -8.4 & 21.7 \\
\cline { 2 - 7 } & Weighted & & -59.9 & & & \\
\hline Urban a) & & 150 & -54.2 & -95.0 & -26.6 & 7.6 \\
\hline Urban b) & & 150 & -53.5 & -120.0 & -14.7 & 11.6 \\
\hline Urban & & 157 & -53.2 & -78.7 & -31.6 & 6.0 \\
\hline Rural & & 155 & -51.6 & -61.8 & -40.1 & 3.6 \\
\hline Outlet & & 162 & -52.6 & -75.2 & -33.5 & 5.2 \\
\hline
\end{tabular}

30

31

32

33

34

35

36

37

38

39

40

41

42

43

44

45

46

47

48

49

50

51

http://mc.manuscriptcentral.com/hyp 
52 Table 3: Best-fit conceptual model simulations and the posterior parameter and performance 53 statistics in terms of the $5^{\text {th }}$ and $95^{\text {th }}$ percentiles around the median.

6

\begin{tabular}{|c|c|c|c|c|c|}
\hline & & \multicolumn{4}{|c|}{ Posterior variability } \\
\hline Parameter & Initial & Best-fit & Median $\left[5^{\text {th }}, 95^{\text {th }}\right]$ & Median KGE Q $\left[5^{\text {th }}, 95^{\text {th }}\right]$ & Median KGE D $\left[5^{\text {th }}, 95^{\text {th }}\right]$ \\
\hline $\mathrm{k}$ & {$[0,0.2]$} & 0.03 & $\begin{array}{l}0.03[0.007, \\
0.038]\end{array}$ & $0.62[0.6,0.65]$ & $0.76[0.58,0.84]$ \\
\hline$\alpha$ & {$[0,0.9]$} & 0.38 & $0.39[0.36,0.78]$ & & \\
\hline$r$ & {$[0,0.5]$} & 0.1 & $0.49[0.05,0.96]$ & & \\
\hline $\mathrm{b}$ & {$[0,0.1]$} & 0.003 & $\begin{array}{l}0.003[0.003, \\
0.08]\end{array}$ & & \\
\hline $\mathrm{u}$ & {$[0,1]$} & 0.31 & $0.26[0.008,0.38]$ & & \\
\hline $\mathrm{MV}_{\text {up }}$ & {$[1,500]$} & 244 & $245[160,265]$ & & \\
\hline $\mathrm{MV}_{\text {low }}$ & {$[500,5000]$} & 507 & $502[500,4531]$ & & \\
\hline
\end{tabular}


74 Table 4: Best-fit lumped convolution integral model (gamma model GM) is compared to the best-fit 75 conceptual model (CM) for simulations at the rural and urban tributaries and the outlet. Also given 76 are the water age statistics in days (MTT $\left.\left[5^{\text {th }}, 95^{\text {th }}\right]\right)$ around the median.

\begin{tabular}{|c|c|c|c|c|c|c|c|c|c|c|c|c|}
\hline \multirow[b]{2}{*}{ Model } & \multirow[b]{2}{*}{$\begin{array}{l}\text { Best- } \\
\text { fit } \\
\text { MTT } \\
\text { (days) }\end{array}$} & \multicolumn{3}{|c|}{ Urban } & \multirow[b]{2}{*}{$\begin{array}{l}\text { Best- } \\
\text { fit } \\
\text { MTT } \\
\text { (days) }\end{array}$} & \multicolumn{3}{|l|}{ Rural } & \multirow[b]{2}{*}{$\begin{array}{l}\text { Best- } \\
\text { fit } \\
\text { MTT } \\
\text { (days) }\end{array}$} & \multicolumn{3}{|c|}{ Outlet } \\
\hline & & $\begin{array}{l}\mathrm{MTT} \\
{\left[5^{\text {th }}\right.} \\
\left.95^{\text {th }}\right]\end{array}$ & $\begin{array}{l}\text { Best- } \\
\text { fit } \\
\text { KGE } \\
(-)\end{array}$ & $\begin{array}{l}\text { Best- } \\
\text { fit } R^{2} \\
(-)\end{array}$ & & $\begin{array}{l}\mathrm{MTT} \\
{\left[5^{\text {th }},\right.} \\
\left.95^{\text {th }}\right]\end{array}$ & $\begin{array}{l}\text { Best- } \\
\text { fit } \\
\text { KGE } \\
(-)\end{array}$ & $\begin{array}{l}\text { Best- } \\
\text { fit } R^{2} \\
(-)\end{array}$ & & $\begin{array}{l}\text { MTT } \\
{\left[5^{\text {th }},\right.} \\
\left.95^{\text {th }}\right]\end{array}$ & $\begin{array}{l}\text { Best- } \\
\text { fit } \\
\text { KGE } \\
(-)\end{array}$ & $\begin{array}{l}\text { Best- } \\
\text { fit } R^{2} \\
(-)\end{array}$ \\
\hline GM & 366 & - & 0.74 & 0.76 & 1150 & - & 0.71 & 0.7 & 456 & - & 0.74 & 0.75 \\
\hline $\mathrm{CM}$ & 163 & $\begin{array}{l}171 \\
{[87,} \\
391]\end{array}$ & 0.86 & 0.89 & 521 & $\begin{array}{l}473 \\
{[326,} \\
864]\end{array}$ & 0.78 & 0.8 & 316 & $\begin{array}{l}280 \\
{[208,} \\
520]\end{array}$ & 0.83 & 0.85 \\
\hline
\end{tabular}

$$
77
$$

78 
Figure 1: Study catchment location with 5 sampling sites and the main current and proposed extent of land uses (Inset shows location in the UK). $137 \times 78 \mathrm{~mm}(150 \times 150 \mathrm{DPI})$ 
Area: $21.3 \%$

Figure 2: Schematic of model structure and spatial distribution according to catchment configuration. Note that the urban percentages correspond to the respective sub-catchment areas (areas in $\mathrm{km}^{2}$ given in Table 1), S and MV are dynamic storage and additional mixing volumes, respectively, and that the actual ET effectively equals PET. Flux equations are given with hydrologic parameters in red and the tracer transport is indicated with additional mixing volume parameters in blue. However, the same parameters were used for the different sub-catchments to maintain a minimum of calibrated parameters (in total 7). $197 \times 137 \mathrm{~mm}(150 \times 150 \mathrm{DPI})$ 
Figure 3: Hydrometric and deuterium isotope daily time series of the study period Oct 2011 to Apr 2014 for a) isotopes and amount of precipitation, b) potential evapotranspiration, c) isotopes and mean simulated discharge at the outlet, and d) discharge isotopes for sites Urban a, Urban b, Urban, and Rural. $162 \times 104 \mathrm{~mm}(150 \times 150 \mathrm{DPI})$ 

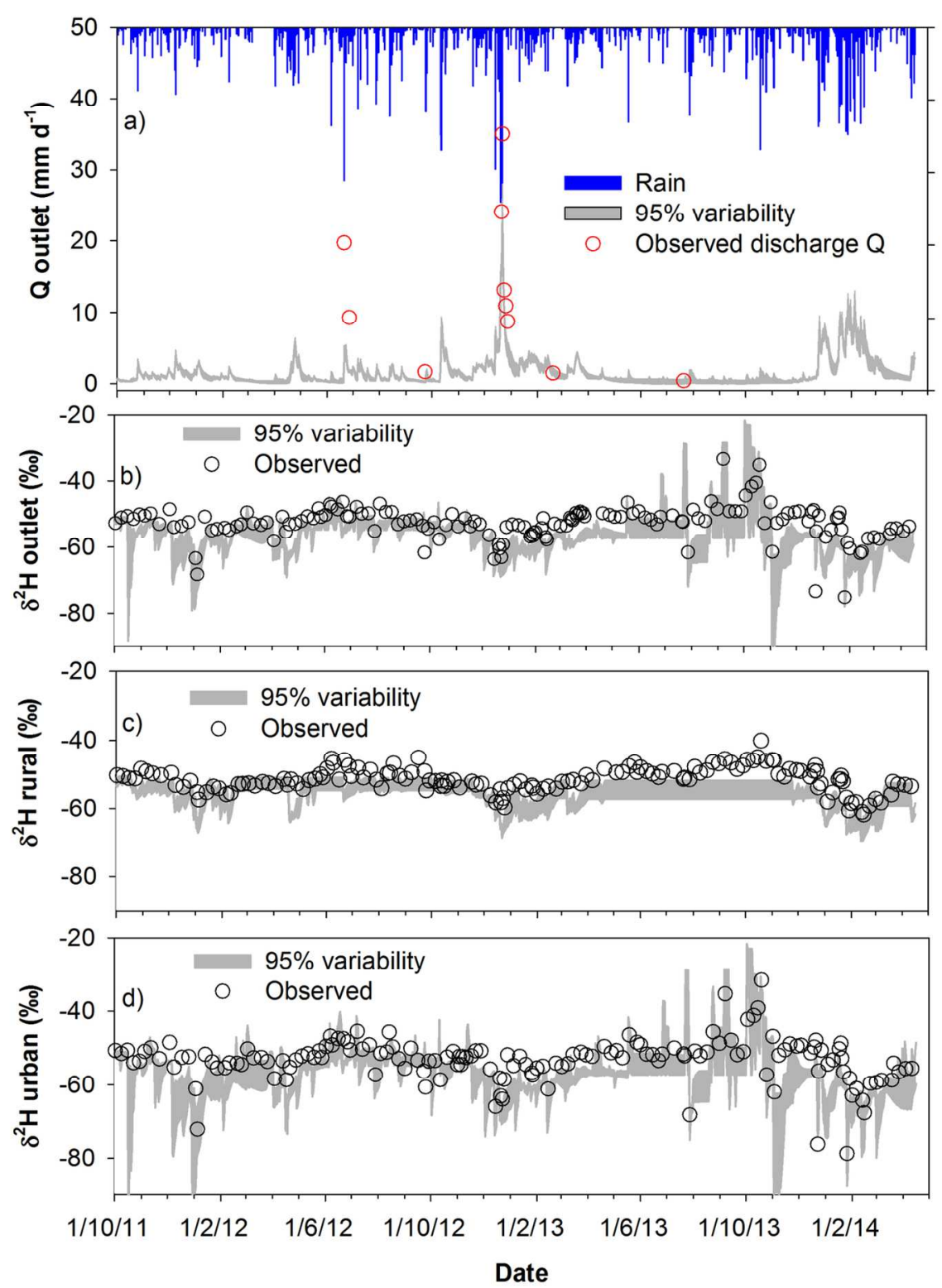

Figure 4: (a) Precipitation and measured and modelled flows at the outlet, together with simulation results showing $95 \%$ posterior parameter variability derived from the best 500 parameter sets for the (b) outlet, (c) rural and (d) urban sites. $254 \times 307 \mathrm{~mm}(150 \times 150 \mathrm{DPI})$ 

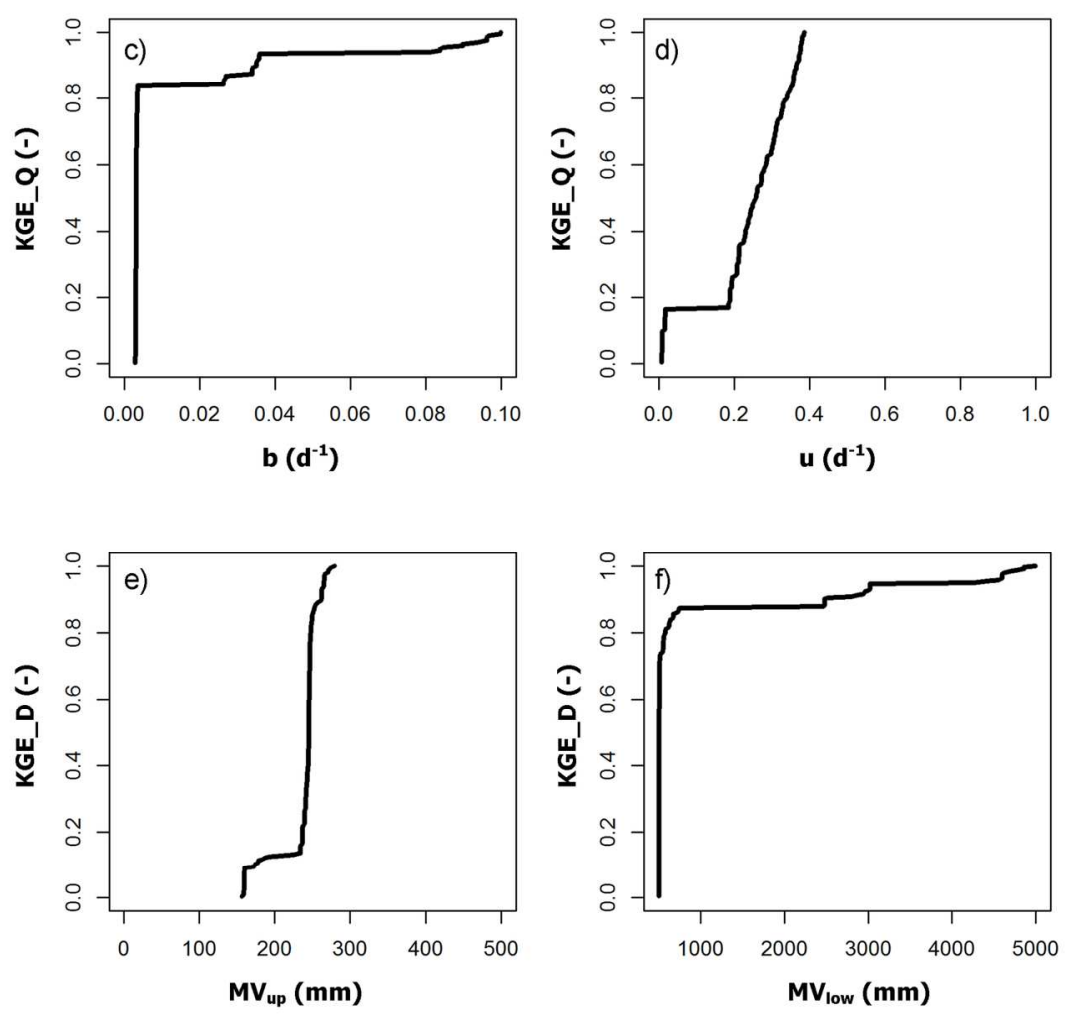

Figure 5: RSA indicates parameter sensitivity for the hydrologic parameters $(k, a, b$, and $u)$ evaluated against the discharge calibration target (KGE_Q) and the tracer parameters (MVup and MVlow) against the isotope calibration target (KGE_D). Increased parameter sensitivity can be derived from stronger curvature compared against a straight line and insensitive parameter. Constrained parameter spaces also indicate parameter sensitivity. Note that the recharge parameter $r$ is not shown here. $270 \times 387 \mathrm{~mm}(150 \times 150 \mathrm{DPI})$ 
Figure 6: Empirical cumulative median flux water age distribution functions (eCDF) are shown for a) the urban area response (sum of all contributing urban areas), b) the urban and c) rural sub-catchments and d) at the outlet. The streamwater age frequency is visualized as histograms ( $a 1, b 1, c 1$ and d1) using identical axes and classes for comparison. $342 \times 370 \mathrm{~mm}(150 \times 150 \mathrm{DPI})$ 


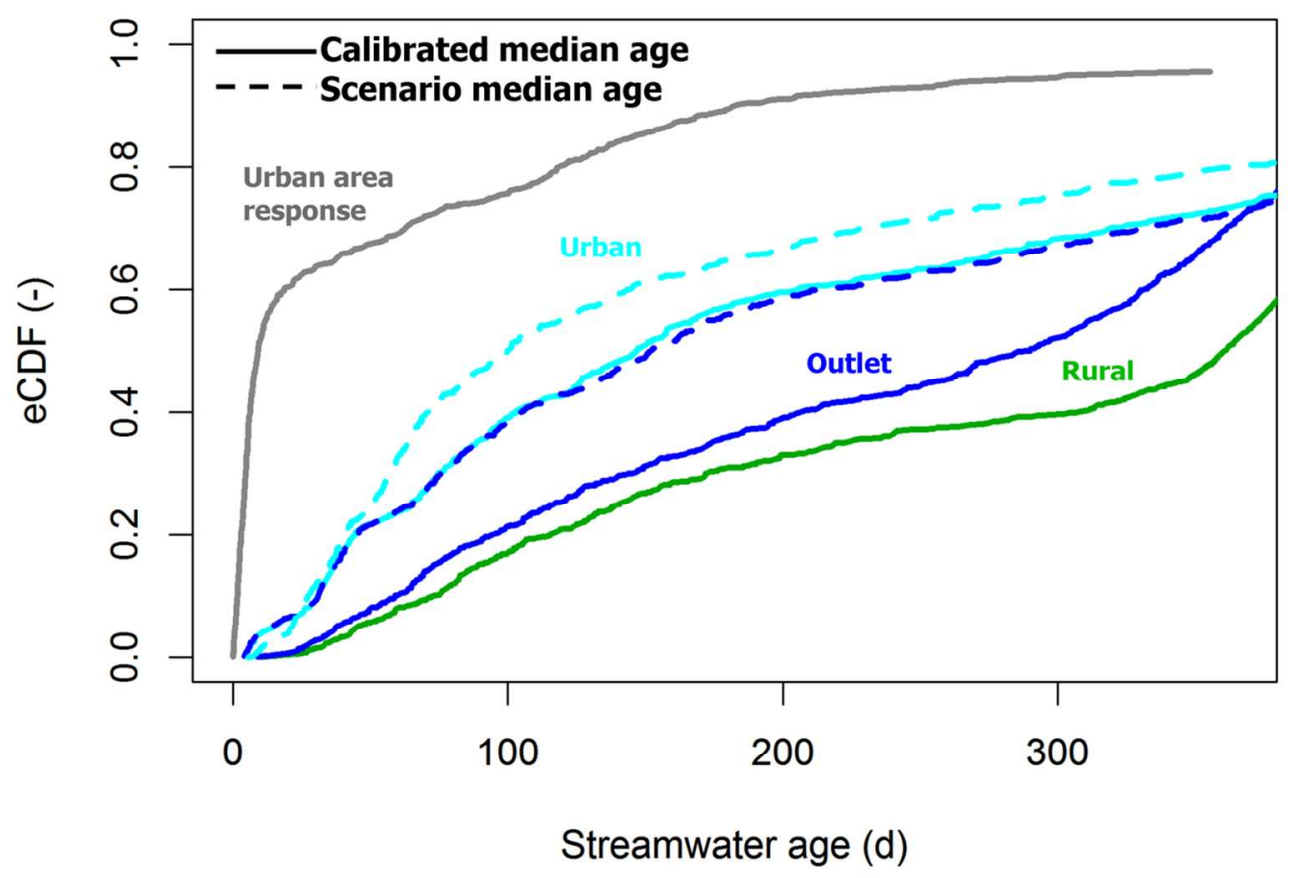

Figure 7: Median water age distributions similar to Figure 6 are compared to scenario water ages (dashed lines) derived from a realistic land use change scenario which will increase the urban cover in the urban subcatchment and at the outlet by a total of almost 3\%. Note that the urban area response refers to the sum of all contributing urban areas. $225 \times 151 \mathrm{~mm}(150 \times 150 \mathrm{DPI})$ 